\title{
A URDA DO TERRITORIO E A TRAMA DA ORALIDADE EN CARLOS CASARES
}

\author{
Marilar Aleixandre \\ Real Academia Galega
}

\begin{abstract}
Resumo: Este traballo aborda o modo en que a trama da oralidade se tece na urda do territorio na narrativa de Carlos Casares, e como o territorio é transformado a consecuencia do acto literario. A análise presta especial atención ás súas primeiras obras Cambio en tres e Xoguetes para un tempo prohibido. O traballo inspírase nos enfoques da xeocrítica que contemplan de forma dialéctica as relacións espazo - literatura - espazo. Discútense estas relacións dinámicas entre territorio e texto literario nas obras de Casares situadas nos espazos da infancia na Limia, Xinzo ou Beiro, e Ourense, e o modo en que a sobriedade do seu estilo reflicte a austeridade deses territorios, así como a súa influencia no autor limiao Antón Riveiro Coello. Analízase o discurso sobre as relacións entre territorio e literatura nos ensaios e textos xornalísticos de Casares, tanto reflexións sobre os espazos da súa infancia na Limia, como sobre estas relacións na literatura doutros autores, nomeadamente Otero Pedrayo. Argumentamos que unha das dimensións dese territorio da infancia de Casares é o discurso oral, os recursos e fontes da tradición oral galega e familiar.
\end{abstract}

\begin{abstract}
This paper examines how the weft of orality is woven into the warp of territory in Carlos Casares' fiction, and how the territory is transformed as a consequence of literary acts. The analysis focuses on his first works as Cambio en tres and Xoguetes para un tempo prohibido. The examination draws on geocritical approaches, which view space - literature - space relationships in a dialectical way. These dynamic connections between territory and literary text, in Casares' novels and short stories, are discussed with particular attention to fiction set in his homeland of the Limia, Xinzo or Beiro and Ourense, and to how his spare style reflects the spare landscape, which in turn influences the fiction of another author from the Limia, Antón Riveiro Coello. Casares' discourse about the relationships between literature and territory in his essays and journalistic pieces is also explored, both considerations about his own childhood's spaces and about these relationships in the literature of other authors as Otero Pedrayo. We argue that one of the dimensions of Casares' childhood
\end{abstract}


territory is oral discourse, sources and resources from Galician and from his own family's oral tradition.

Palabras chave: Carlos Casares, territorio, xeocrítica, oralidade, narrativa, austeridade.

Key words: Carlos Casares, territory, geocriticism, orality, fiction, austerity.

Ten a seguridade de que a paisaxe que el [Otero Pedrayo] divisa desde a súa casa de Trasalba é moi distinta da que se describe en moitos libros e crónicas, o que lle resulta difícil de comprender. Non sabe aínda que a paisaxe non é un obxecto exterior autónomo, independente do individuo, senón unha "obra do corazón”, como dixo Rilke.

Carlos Casares, Un país de palabras (1998:160).

\section{A DIMENSIÓN IMAXINARIA DOS ESPAZOS LITERARIOS}

Carlos Casares afirma que a paisaxe "non é un obxecto exterior, autónomo, independente do individuo" en 1998, dous anos antes de Bertrand Westphal (2000) iniciar o enfoque xeocrítico que analiza o modo en que a literatura asimila o espazo e, ao mesmo tempo, as transformacións do espazo en función do texto literario. O ensaio, que forma parte do volume Un país de palabras titúlase significativamente "Un inventor de paisaxes" e narra o descubrimento, por parte de Otero Pedrayo, do mapa de Fontán co nome da súa aldea, Trasalba, e as serras que a rodean, A Martiñá, A Magdalena e O Suído. Segundo outro autor relevante da perspectiva xeocrítica, Robert Tally (2012), é facendo uso dos mapas, xunto coa observación e a imaxinación, como un lugar cobra sentido para nós. Otero é recoñecido por Casares como inventor da paisaxe galega. Desde unha posición explicitamente ancorada na xeocrítica, María López Sández (2008) examina a creación discursiva do territorio galego e o papel nela de Otero -continuando o de Rosalía de Castro, recoñecida como primeira creadora da paisaxe-, analizando o peso textual da paisaxe, e o camiño como mecanismo narrativo estruturante na novela Arredor de si.

Sustenta Casares esta idea da paisaxe como invención ou transformación na noción da "obra do corazón" (Herz-werk) proposta en 1914 por Rainer Maria Rilke no poema "Wendung" (viraxe), incluído nunha carta a Lou Andreas Salomé: "Concluída está a obra da mirada / emprende agora a obra do corazón". Rilke, poeta de cegadora intensidade, é tamén, xunto con Kafka, un dos autores que elaborou máis lúcidas reflexións sobre a escrita. Nunha carta a Witold Hulewicz 
sobre as Elexías de Duino fala explicitamente das transformacións executadas pola escrita; quen escriben son "abellas do invisíbel" (die Bienen des Unsichtbaren):

As cousas deben ser comprendidas e transformadas por nós. Transformadas? Si, pois a nosa tarefa é esta: impregnarnos desta terra provisional e caduca, tan fondamente, tan doentemente, tan apaixonadamente, que a súa esencia rexurda outra vez en nós, invisíbel. Somos as abellas do invisíbel (Rilke, 13 de novembro de 1925).

Estas ideas adiántanse, en certa medida, á perspectiva xeocrítica, da que o texto "Pour une approche géocritique des textes" de Westphal no 2000 é considerado o manifesto fundacional. Westphal parte da crítica á ollada colonialista que contempla o espazo desde un só punto de vista, pois o espazo colonial está referenciado ao centro. Argumenta que os espazos cambian mais, sobre todo, é o modo de representación o que mudou. Un exemplo clásico son os mapas baseados na proxección de Peters, hoxe denominada Gall-Peters, recoñecendo tanto a James Gall, que a propuxo en 1855, como a Arno Peters que a popularizou en 1970 a través de mapas. A proxección Gall-Peters pretende representar países e continentes de acordo cos seus tamaños relativos, ao contrario dos distorsionados mapas baseados na proxección de Mercator onde o hemisferio sur parece máis pequeno do que é. Mais a nosa visión do mundo foi construída a través de Mercator. A xeocrítica está pois ancorada en correntes anteriores como o revisionismo cartográfico (Thieme 1998) e a teoría literaria poscolonial (Pratt 1992). Tally (2008) caracteriza a xeocrítica como un marco teórico centrado nas representacións espaciais nos textos, que examina en particular os solapamentos entre os territorios reais, da xeografía física e do mapa mental dun autor ou autora, ou dun personaxe no texto literario. Para Tally (2012) estar no mundo é localizarse unhas persoas en relación a outras. Proxectamos liñas imaxinarias que trazan espazos xeográficos de referencia, ou inventan narrativas e, como indica Tally, a latitude e a lonxitude son exemplos destas liñas imaxinarias.

Non sempre é recoñecida, engadiría eu, a natureza imaxinaria ou convencional de meridianos ou fronteiras. Nunha viaxe no sueste asiático compartida cunha socióloga chinesa de Singapur e dous antropólogos británicos, tomamos parte nunha acendida discusión entre un exilado de Myanmar (nome colonial, Birmania), pertencente á etnia Shan, e un dos antropólogos. O pobo Shan vive entre Myanmar, China, Laos e Tailandia, e resultou separado polas fronteiras impostas nos acordos coloniais entre Inglaterra e Francia. $O$ exilado Shan intentaba explicar ao británico por que el non era, nin se sentía, "birmano", dado que non pertencía aos Bamar, grupo étnico dominante. Cómpre indicar que hai 135 grupos étnicos 
recoñecidos no país, que falan linguas tan diversas como as do tronco chinés-tibetano e as indoeuropeas. "Mais as fronteiras... no tempo do imperio" argumentaba o británico, ao que o Shan, logo de preguntar con retranca "que imperio?", respondía que el non aceptaba esas fronteiras e que tiña familiares en Laos ou en Tailandia que cruzaban polos camiños da selva sen coidarse das fronteiras. $\mathrm{O}$ carácter histórico e convencional das fronteiras, idea que o británico se negaba a aceptar, cobra especial relevancia en contextos coloniais ou poscoloniais.

En canto aos meridianos, cómpre lembrar que a adopción de Greenwich como meridiano cero - por certo coa abstención de Francia e Brasil-data de 1884, e que antes dese ano coexistían o Meridiano de París (citado por exemplo nas novelas de Jules Verne), o de Moscú ou o da Isla del Hierro, que chegou a ser denominada como Illa do Meridiano. Westphal (2016) titula o seu libro máis recente La cage des méridiens (A gaiola dos meridianos) no que, en liña coa súa crítica do colonialismo e da visión occidental hexemónica, analiza a institución do canon literario como un intento de elevar o modelo das prácticas occidentais a referente universal.

Podemos preguntarnos se é a Raia unha destas liñas imaxinarias. Sobre todo a Raia seca, pois o Miño ten natureza física, para alén da literaria. Non me atrevería a afirmar ser ou non Xinzo parte da Raia, e preguntado Antón Riveiro Coello, a quen me remito como fonte de autoridade no referente a Xinzo, dime que non. Se a Raia existe como fronteira, como espazo común a ambos lados dela, desde os tempos de Afonso Henriques no século XII, non é menos certa a existencia de formas lingüísticas, sotaques, tradicións como o Entroido / Entrudo, receitas, cancións compartidas. Un dos escritores máis admirados por Casares foi Miguel Torga, como narra noutro dos ensaios d'Un país de palabras.

En resumo, a referencia á dimensión imaxinaria dos espazos literarios, non debe entenderse de forma negativa. Concordamos con María López Sández (2008) en considerar o imaxinario en relación co mito e o símbolo. Parafraseando a Tally (2012) podemos dicir que a imaxinación é unha das tres ferramentas -xunto cos mapas e a observación-, ou heurísticas mediante as que facemos que un lugar cobre sentido. Tanto cobran sentido por medio delas que, segundo Benedict Anderson (1983), non lles foi posíbel ás persoas imaxinar as nacións até dispoñeren de mapas, até contemplaren nun mapa o seu país representado, por exemplo, cunha cor diferente á do país veciño. En palabras de Westphal (2000) "les espaces humains ne deviennent pas imaginaires en intégrant la littérature; c'est la littérature qui leur octroie une dimension imaginaire, ou mieux: qui traduit leur dimension imaginaire intrinsèque en les introduisant dans un réseau intertextuel". 


\title{
A URDA DO TERRITORIO NA NARRATIVA DE CARLOS CASARES: A CONSTRUCIÓN DA AUSTERIDADE
}

\begin{abstract}
Desde entón, a beleza da paisaxe galega estará para el [Otero Pedrayo] na pedra, non no verdor do manto vexetal. Os granitos da Galicia occidental pensa el que conforman unha lei da paisaxe que ten a súa manifestación máis regular nunha tendencia perpetua á esfericidade. As chairas son curvadas, igual que as ladeiras dos rochedos, e as serras alongadas parécense ao espiñazo das vacas (Casares 1998: 160-161).
\end{abstract}

Conclúe Casares esta análise, afirmando que pedras, rochas, granitos ou lousas son para Otero Pedrayo "os elementos que definen dunha maneira máis exacta a paisaxe galega, moito máis que os bosques e os prados”. Apunta María López Sández que, en función dos imaxinarios culturais, a nación ancoraríase na xeoloxía, no substrato natural. Nun ensaio sobre a paisaxe galega (Aleixandre 2017) escóitase en primeiro lugar o que denomino "a voz das rochas". Son significativas as metáforas empregadas por Otero Pedrayo (1955) para falar dos granitos, rochas "fillas do lume", e das lousas "follosas como códices". Se nas follas destes códices está, segundo as teorías xeolóxicas, a memoria da Terra, podemos entender que para Otero está así mesmo a memoria da paisaxe e do país. Aínda que tamén, na súa visión, a auga é un elemento relevante xa que vai "concedendo voz ás paisaxes". A narrativa de Carlos Casares non pode interpretarse como ancorada na xeoloxía, mais a urda na que se tece é a do territorio.

Ese territorio é nomeadamente a Limia da súa infancia, Xinzo, Beiro, Lamas ou Porqueira, e mais Ourense, mais tamén o de Cangas, onde viviu e ensinou -coa interrupción do seu tempo como deputado- durante nove anos, desde 1974. Ao apropiarse destes territorios para a súa ficción transfórmaos en espazos cargados de simbolismo. Así o Xinzo de Xoguetes para un tempo prohibido (Casares 1975) ${ }^{1}$ simboliza o paraíso perdido da infancia, ao que se fai referencia explícita tanto na cita de Jean Paul Sartre que abre o libro, como no propio texto. Un paradoxo, no caso dun escritor que na súa autopoética (Casares 2003) considérase a si mesmo un narrador que opta pola transparencia, e que prefire a ironía, rexeitando tanto o "dogmático e serio", como o simbólico, no que é interpretado por Bermúdez (2009) e Monteagudo (2003), como unha aposta polo realismo. Nesa mesma autopoética Casares opón o seu afán de sinxeleza coa "exuberancia imaxinativa" de escritores como Álvaro Cunqueiro, a solemnidade e o dramatismo frecuentes

1 As citas das novelas Cambio en tres, Xoguetes para un tempo prohibido e Ilustrísima corresponden ás primeiras edicións, consultadas na biblioteca de Juan López de Toba. 
na literatura co seu obxectivo de escribir novelas con carácter de parábolas contra o dogmatismo, a favor da humanidade.

Suxiro que esta austeridade ou sobriedade do estilo de Casares relaciónase de forma dialéctica coa sobriedade das paisaxes da Limia, ou máis precisamente coa austeridade destas paisaxes recreadas na súa narrativa, en contraposición ao dramatismo e a exuberancia doutras paisaxes galegas, como poderían ser as da Costa da Morte. Así, é nun relato situado no Morrazo, Un polbo xigante, onde cabe apreciar notas máis dramáticas, acordes coa paisaxe do Cabo Udra. Cómpre ter en conta que esta construción da sobriedade por parte de Casares non implica a Limia ou Ourense seren evocados unicamente como territorios austeros ou cun estilo austero, pois non ocorre así noutros autores ourensáns máis barrocos.

En Cambio en tres (Casares 1969) a presenza da cidade de Ourense é dominante e a paisaxe física na que está situada evócase apenas nuns trazos: "alá lonxe, por detrás da Serra aparece unha nube negra, debe ser negra, de tronada.” (1969: 19). A evocación constrúese tamén a través doutros elementos da paisaxe, así as continuas referencias á calor abafante, non sempre negativas: "Era unha animalada, pero había como unha alegría quente saltando no calor da tarde" (1969: 24), ao inicio da descrición do acoso colectivo a unha rapaza que desencadeará os acontecementos da novela. A calor "que se volve insoportable, quén tería a ocurrencia de construir eiquí un pobo" (1969: 72) oponse ao frescor do río, ao mergullo na auga, imaxe do pracer, da sensualidade, tanto nesta novela como n'O sol do verán (Casares 2002), ou en Ilustrísima (Casares 1980), cando o bispo divisa aos mozos bañándose no río: "Sentiu entón unha especie de chamada sensual e pagana que o obrigou a recitar para si unha xaculatoria" (1980: 19). O contacto da auga co corpo simboliza o gozo, mesmo a da mangueira caendo sobre o corpo na obra onde o Cachorro é albanel, ou a da xerra no cuarto da casa, tan pracenteira que o Lisardo decide non secarse "estáse así millor, ca auga resbalando polo corpo, qué ben se sinte ún” (1969: 83). Tamén a luz entrando pola fiestra contrasta cos "neboentos recunchos" das Covas, onde se refuxia o Cachorro logo da malleira ao Cascón. Nas Covas encontra unha pistola que causará a morte do Alemán e o castigo para o Cachorro, enviado ao internado.

Cambio en tres, Ilustrísima e Deus sentado nun sillón azul transcorren en Ourense, e delas a primeira é a máis ourensá; a cidade é transformada pola súa palabra, sendo hoxe posíbel camiñala nun roteiro Carlos Casares elaborado por Afonso Vázquez-Monxardín (2017) que percorre os escenarios da súa narrativa. Un dos mecanismos para a transformación do territorio en texto literario é que a identificación está referenciada por nomes de rúas, prazas ou cafés, non polo da vila ou cidade, citado en Cambio en tres unha soa vez, paradoxalmente cando o Cachorro está deixándoa, logo de "saír da estación de Ourense” (1969: 54) 
no tren que o leva ao internado. A ausencia de localización explícita, estratexia empregada tamén por outros autores e autoras, converte o lugar nun arquetipo. Outra práctica que contribúe nesta transformación é a forma de nomear elementos da paisaxe, a Serra, as Covas, que teñen carácter xenérico e poderían pertencer a calquera cidade. Escríbense con maiúscula inicial que parecería denotar unha Serra ou Covas específicas, mais sen engadir topónimos que permitirían a identificación. Dun modo sutil isto conéctase na novela cos nomes de rúas, prazas ou parques máis citados, rúa do Paseo, a Alameda ou a Praza Maior, que poden semellar arquetípicos, existentes noutras vilas, mais que neste caso si corresponden á cidade de Ourense.

Se en Xoguetes para un tempo prohibido a localización en Xinzo é máis explícita, a evocación da paisaxe é igualmente austera: "volvías á terra prometida [...] pero Yaveh Deus tivo compasión e alí estaba novamente a chaira longa e larga das méses agardándote" (1975: 53). A chaira das méses resoa coa chaira da paisaxe limiá e mesmo coa chaira interminábel dos anos por vir. Porén, os elementos urbanos pertencen inequivocamente ao Xinzo dos anos 40, como a Praza do Pescado -á que o autor fai referencia no artigo "A labazada" publicado en "Á marxe", na Voz de Galicia o 17 de marzo de 1995- o café Moderno ou o cine Molinos. Esta relación é analizada por Antón Riveiro Coello (2017) nun artigo sobre as lembranzas da infancia na escrita de Casares. $\mathrm{O}$ uso dos topónimos é máis impreciso que o das rúas, os montes da Pereira corresponden a Rairiz de Veiga, o Portelo está tirado doutra vila ourensá, e a Fontemoura situada na Porqueira, perto de Beiro. En Beiro pasou longas tempadas nos veráns, co seu padriño Xosé Mouriño, e dela fará a localización da súa derradeira novela, $O$ sol do verán, na que Beiro é, como o Xinzo de Xoguetes, o paraíso da infancia.

Estas dúas novelas constitúen exemplos dun estilo sobrio, no que a relación co territorio é construída principalmente por alusións. A influencia desta forma de escribir, contida, transparente, maniféstase na narrativa doutro autor limiao, Antón Riveiro Coello, particularmente na novela A ferida do vento, situada en Xinzo, que desde o título constitúe unha homenaxe a Casares.

\section{RECURSOS E FONTES DA TRADICIÓN ORAL: OS AVÓS}

Carlos foi un grande fabulador, utilizando fábula no seu significado máis amplo, de historia de ficción e fabulador no de creador de historias: "Se me preguntan o que son respondo: un contador de historias", definición utilizada no título da biografía escrita por Henrique Monteagudo (2017). A trama da oralidade, de "contar", entretécese pois na urda do territorio na súa narrativa acadando, como apunta Xavier Carro (2003) a proximidade con quen le. 
No ensaio "Os meus avós e a literatura" d'Un país de palabras, Carlos reflexiona sobre a influencia dos avós paternos Herminio Casares e Francisca Dacal, sobre todo do primeiro, na súa forma de escribir. Os avós vivían en Lamas, unha parroquia de Xinzo a tres quilómetros da vila, un dos territorios da infancia do escritor. Casares contrasta as formas de narrar de Herminio, realista, ancorada en episodios presenciados ou vividos, e Francisca, proclive ao misterio e a historias sobre o trato doméstico cos mortos. É a atención aos detalles e o pracer de narrar o que aprende do avó: "No caso da cabalgada sanguenta do meu avó sempre lla oín contar do mesmo xeito: $\mathrm{O}$ relato, prolixo de datos e narrado cun ritmo lento, case parsimonioso, no que resultaba evidente o pracer que lle producía o propio acto de narrar os feitos" (1998: 135). Nesta "minuciosidade dos detalles" radica o interese da historia, a súa verosimilitude. Porén, aínda sendo certa a atención aos detalles, non o é a pouca importancia da orde cronolóxica, o tempo que segundo o ensaio "simplemente non existe". Cambio en tres, como grande parte da narrativa contemporánea comeza in media res, cunha voz narradora omnisciente, substituída axiña polo monólogo interior de Lisardo, que vai lembrando alternativamente os momentos anteriores ao accidente e a súa infancia, cando coñeceu o Cachorro.

A densidade nos detalles maniféstase por exemplo no episodio da morte do maquis en Xoguetes para un tempo prohibido:

tres ou catro tiros apenas distinguidos entre o berrar da xente, e a figura daquel mozo de roupas rotas e pelo loiro correndo a traspés polas airas, que foi morrer amodiño, amodiño ó pé dunha meda grande, rodeado de xente e de cás que lle cheiraban un pé descalzo mentras as moscas se lle pousaban na cara e recorrían pra riba e pra baixo o fío negro que lle iba dende a frente hastra o pescozo. (1975: 22).

Nun rexistro menos tráxico, o interese polos detalles é explicitamente aludido polo narrador d'Un polbo xigante. A muller -ou viúva- de Nicolás pídelle ao narrador "Cóntame como sucedeu todo", ao que Delfina engade: "que fixese un esforzo para lembralo todo, sen omitir nada, nin tinto nin colorado: 'Non deixes nada no tinteiro'. Cun movemento de cabeza prometín contar con todo detalle. Daquela a muller de Nicolás preguntoume: ‘De que parte ventaba o día do suceso?’” (2000: 18).

Casares apunta á influencia do avó nas súas primeiras obras: "que me levou a narrar os meus primeiros contos da mesma forma que o meu avó me contaba os episodios máis destacados da súa longa vida" (1998: 136). Os recursos da tradición oral están máis presentes nas primeiras novelas, Cambio en tres ou Xoguetes para un tempo prohibido, mais tamén nas obras ilustradas, publicadas "fóra de 
colección”, O galo de Antioquía (1994) e Un polbo xigante (2000), que na miña opinión non poden considerarse estritamente como narrativa infantil nin xuvenil; Monteagudo na súa biografía tampouco as contempla como parte dela.

Así, o rexistro oral, coas interrupcións e dúbidas da voz narradora no inicio de Cambio en tres:

A última vez que estuvo nesta habitación pérdeselle xa na lembranza, un pouco lonxe, hai catro anos, non, aínda non, fará catro anos pró 24 do mes que entra, sí, catro anos pró 24 de agosto. (1969: 13).

\section{Ou en Xoguetes para un tempo prohibido:}

porque hai leises que regulan as preferencias das rapazas polos rapaces que nunca chegarás a entender por moito que Chedes lle diga a Olga eso que Olga lle dixo á túa irmá e que a túa irmá non cho quere decir a ti anque ti lle prometas que si cho di, tamén ti lle contarás outra cousa que ela quere saber, pero que non lle contas nin siquera despois de confesar ela que Chedes quere ir contigo ó cine porque lle gustas. (1975: 63).

Dicir que O galo de Antioquía e Un polbo xigante están modelados na tradición oral non significa que sexan unha reescrita de contos ou lendas populares, pois ambos son historias plenamente orixinais. Un polbo xigante é un híbrido que sitúa o mito do Kraken no contexto, tan querido por Carlos, do cabo Udra e a ría de Aldán. Ben podía ser contado a carón do lume a noite en que comeza a historia, a resgardo da viruxe, a salvo dos perigos que axexan no mar escuro, nese intre no que as historias de medo son máis engaiolantes. A ambigüidade do relato pode levar a pensar que talvez a historia do polbo xigante non a inventou Carlos, senón a vella Delfina, quen posúe a capacidade de convencer ao narrador de que el mesmo vira un polbo grande como dez vacas, ou de que oíra asubiar a Alborada de Veiga entre o bruar dos tombos. Pois as historias ben contadas acaban persuadíndonos de seren certas. En Un polbo xigante hai ecos de Pericles e a balea de Xohana Torres (1984), considerada por Carme Blanco (1991) a primeira narración feminista da literatura galega. O churreiro Pericles marcha, xunto co seu can Argos, navegar cunha noiva singular, a balea Tálata. Pericles o churreiro pode ser un antecedente do criado Nicolás que, segundo unha das versións da historia, marchou viaxar cun polbo. Mais tamén, di Delfina, o que semellaba un polbo pode ser o xastre de Agüeiros "que se viste moitas veces dese papel". 
As boas historias de medo serven para escorrentar o medo, e a viúva do Nicolás, logo de escoitala, dá por finalizado o velorio, pois seu home non está afogado, senón de viaxe polos Mares da China ou vai cara á festa de San Roque na Pobra.

N'O galo de Antioquía entretécense a lenda da cidade de Antioquía asolagada baixo a lagoa de Antela, coa crítica á intolerancia, representada pola Inquisición, o canto á diversidade, como n'A galiña azul, e o rexistro absurdo ou surreal, así a capacidade do ferreiro o Calatrón de poñer ovos. Publicado por vez primeira en 1994, como parte dos Contos do Castromil, foi recuperado no número 3 da revista Lethes. Cadernos culturais da Limia, poucas semanas antes da morte de Carlos. Antioquía é unha das moitas cidades lendarias asolagadas en Galicia, como Beira, baixo a lagoa de Cospeito, ou Duio, en Fisterra. Disque esta última foi asolagada polo apóstolo Santiago en castigo ao paganismo, mais segundo a xente de Mallas foi o emperador Carlomagno, ou Calromán, como é chamado en Fisterra, quen enrabechado logo de poñer en van sitio a Duio pronunciou este esconxuro:

Ouh cidá eu te asolagho

co de arriba para abajo

O que fai máis plausíbel esta versión é o castrapo no que está enunciada, pois Calromán non estaba moi dotado para as linguas. Noutro lugar (Aleixandre 2003) dou conta dunha versión alternativa que atribúe á propia cidadanía de Duio o encantamento para evadir o cerco.

Ecoa tamén n’O galo de Antioquía a historia do sancristán / barbeiro de Lugo que, como o Calatrón, cantaba o quiquiriquí, no relato "Lisardo Montes" que forma parte d'Os outros feirantes (Cunqueiro 1979). En "Se Cunqueiro fose Eurípides", parte d'Un país de palabras, Casares fai referencia ao uso do latín como elemento humorístico neste relato, un recurso tamén empregado n'O galo de Antioquía cando o Calatrón é quen de responder a preguntas en latín sobre o tempo transcorrido desde o Diluvio Universal (catro mil setecentos anos, seis meses e quince días) ou a data exacta da creación do mundo. O coñecemento do latín é, para don Luís, o cura que o denunciará á Inquisición, proba de que o Calatrón ten o demo, unha chiscada máis de Casares á oposición entre coñecemento e intransixencia.

Carlos Casares foi un grande narrador oral ("fabulador", di Arcadio López-Casanova no seu artigo neste mesmo número), utilizando material da vida, a súa ou doutros, da infancia, reinventando e modificando as historias cada vez que as contaba; contando como propias anécdotas que lle ocorreran a outros. As historias son boas cando están ben contadas e Carlos era insuperábel contando historias reais, inventadas ou roubadas. Como ao seu avó, producíalle pracer o propio acto de 
narrar, pois á fin escribimos para nós mesmos, mais escoitalo era un pracer. A oralidade é pois unha das dimensións dese territorio da infancia de Casares que contribúen á construción dun mapa literario e emocional propio. Sen dúbida un dos trazos do territorio da Limia e do territorio galego, que forma parte do imaxinario de quen o habitan, é a lingua galega e a forma na que é empregada polos falantes.

En resumo, na escrita Carlos Casares bota man da súa engaiolante capacidade para contar historias oralmente, nas sobremesas, tertulias, noites de Verines, viaxes en coche ou calquera outra situación que fornecese unha oportunidade de narrar. A súa ficción leva á práctica a advertencia de Isak Dinesen no conto "A páxina en branco": cómpre ser fiel á historia.

\section{AGRADECEMENTOS}

Ao proxecto "Ecoficcións", financiado polo MINECO-FEDER, código FEM201566937-P. A Antón Riveiro Coello, que con paciencia aclarou as miñas dúbidas sobre Xinzo de Limia, e a Alcázar López Facal que puxo escola en Mallas e me transmitiu o texto do esconxuro de Calromán.

\section{REFERENCIAS BIBLIOGRÁFICAS}

Aleixandre, Marilar (2003): A Vaca de Fisterra e a trabe de alcatrán. Zaragoza: Tambre / Edelvives.

(2017): Voces termando da paisaxe galega. A Coruña: Real Academia Galega. Discurso de Ingreso na Real Academia Galega.

Anderson, Benedict (1991 [1983]): Imagined communities: Reflections on the origin and spread of nationalism. London: Verso.

Bermúdez Montes, María Teresa (2009): "Ecos e lecturas da narrativa europea contemporánea na obra de Carlos Casares", en Camino Noia, Olivia Rodríguez e Dolores Vilavedra (eds.), Actas Simposio Carlos Casares. [S.1.]: Fundación Carlos Casares, 11-30.

Blanco, Carmen (1991): Literatura galega da muller. Vigo: Edicións Xerais de Galicia.

Carro, Xavier (2003): "Un escritor na marxe de cada día”, en Francisco Díaz-Fierros Viqueira e Henrique Monteagudo (eds.), Carlos Casares: a semente aquecida da palabra. Santiago de Compostela: Consello da Cultura Galega, 142-143. Casares, Carlos (1969): Cambio en tres. Vigo: Galaxia.

(1975): Xoguetes pra un tempo prohibido. Vigo: Galaxia.

(1980): Ilustrísima. Vigo: Galaxia.

(1998): Un país de palabras. Vigo: Galaxia. 
(2000): Un polbo xigante. Vigo: Galaxia.

(2002): O sol do verán. Vigo: Galaxia.

(2003): O galo de Antioquía. Vigo: Galaxia.

(2003): "O morcego e as bolboretas. Ensaio de autopoética", en Fran-

cisco Díaz-Fierros Viqueira e Henrique Monteagudo (eds.), Carlos Casares:

a semente aquecida da palabra. Santiago de Compostela: Consello da Cultura Galega, 273-277.

Cunqueiro, Álvaro (1979) Os outros feirantes. Vigo: Galaxia.

Dinesen, Isak (1986 [1955]): “The blank page”, en Last tales. London: Penguin, 99-105.

López Sández, María (2008): Paisaxe e nación: a creación discursiva do territorio. Vigo: Galaxia.

Monteagudo, Henrique (2017). Carlos Casares. Un contador de historias. Vigo: Galaxia.

Otero Pedrayo, Ramón (2009 [1955]): "Ensaio sobor da paisaxe galega", en Ramón Otero Pedrayo [et al.], Paisaxe e cultura. Ensaios. Vigo: Galaxia, 47-105. Pratt, Mary Louise (1992): Imperial eyes: Travel writing and transculturation. Abingdon: Routledge.

Riveiro Coello, Antón (2016). A ferida do vento. Vigo: Galaxia. - (2017). "Carlos na vila", Lethes. Cadernos culturais da Limia 13, 27-30.

Tally, Robert T. (2008): "Geocriticism and classic American literature", en Faculty Publications. Texas: State University. Dispoñible en https://digital.library.txstate.edu/handle/10877/3923.

(2012): "Sobre la cartografía literaria". Cuadrivio 8. Dispoñible en https:/cuadrivio.net/sobre-la-cartografia-literaria/

Thieme, John (1998): "Cartographical revisionism in the New Literatures in English”, en C. C. Barfoot, e Theo D'haen (eds.), Oriental Prospects. Western Literature and the Lure of the East. Amsterdam: Rodopi, 225-237.

Torres, Xohana (1984): Pericles e a balea. Vigo: Galaxia.

Vázquez-Monxardín, Afonso (2017): Roteiro Carlos Casares. Ourense: Concello. Dispoñible en http://turismodeourense.gal/wp-content/uploads/2017/02/ Folletos_web-1.pdf

Westphal, Bertrand (2000): "Pour une approche géocritique des textes", en Bertrand Westphal (ed.), La géocritique, mode d'emploi. Limoges: Presses Universitaires. [Reproducido en Vox Poetica, http://www.vox-poetica.net/sflgc/ biblio/gcr.html].

- (2016): La cage des méridiens. La littérature et l'art contemporain face à la globalisation. Paris: Les Éditions de Minuit. 